\title{
Control over Catenation in Pillared Paddlewheel Metal-Organic Framework Materials via Solvent-Assisted Linker Exchange
}

Wojciech Bury, ${ }^{\dagger, \ddagger}$ David Fairen-Jimenez, ${ }^{\S} \|$ Marianne B. Lalonde, ${ }^{\dagger}$ Randall Q. Snurr, ${ }^{\S}$ Omar K. Farha, ${ }^{*}{ }^{\dagger}$ and Joseph T. Hupp*, ${ }^{\dagger}$ Department of Chemistry and International Institute for Nanotechnology, Northwestern University, 2145 Sheridan Road, Evanston,
Illinois 60208, United States
${ }^{\ddagger}$ Department of Chemistry, Warsaw University of Technology, Noakowskiego 3, 00-664 Warsaw, Poland
${ }^{\S}$ Department of Chemical and Biological Engineering, Northwestern University, 2145 Sheridan Road, Evanston, Illinois 60208,
United States
${ }^{\|}$Department of Chemical Engineering and Biotechnology, University of Cambridge, Pembroke Street, Cambridge CB2 3RA, United
Kingdom

Supporting Information

ABSTRACT: Control over catenation in a pillared paddlewheel metal-organic framework was achieved via solventassisted linker exchange. The linker exchange was demonstrated on the noncatenated structure of DO-MOF, by using 4, $4^{\prime}$-bipyridine (L4) and 4, $4^{\prime}$-azobis(pyridine) (L5) as linkers, leading to noncatenated materials SALEM-3 and SALEM-4. The de novo synthesized analogues of SALEM-3 and SALEM4 can only be obtained as 2 -fold interpenetrated frameworks. The reaction progress of the linker exchange was monitored by NMR spectroscopy, and structure and framework catenation were characterized by powder X-ray diffraction and thermogravimetric methods.

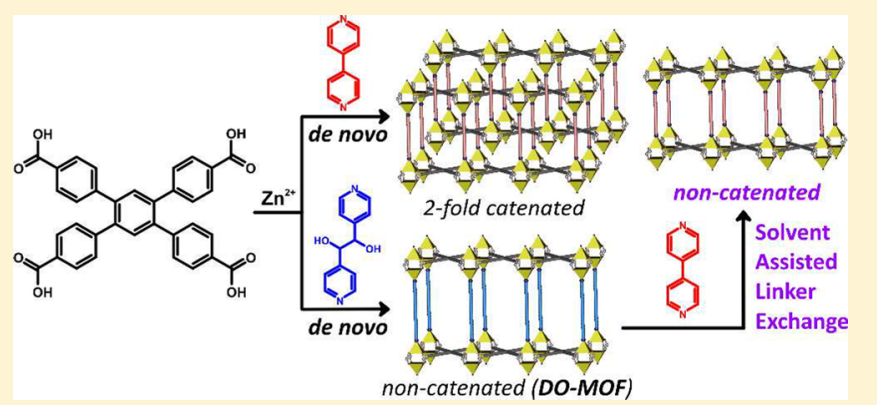

KEYWORDS: catenation, metal-organic frameworks, SALE, linker exchange

\section{INTRODUCTION}

Metal-organic frameworks (MOFs) are crystalline, porous materials composed of organic linkers and metal-cluster or metal-ion nodes. ${ }^{1}$ They have become popular targets for investigation due to their ultrahigh surface areas ${ }^{2}$ and their wide range of potential applications, such as gas storage and separation, ${ }^{3,4}$ sensing, ${ }^{5,6}$ and catalysis. ${ }^{7}$ In many MOF syntheses, especially ones where one or more of the linkers is lengthy and narrow, high degrees of framework catenation (i.e., interpenetration, or more commonly, interweaving) are obtained. ${ }^{8}$ Under particular circumstances, for some applications, such as selective guest capture, ${ }^{9}$ stepwise gas adsorption, ${ }^{10}$ photoluminescence control, ${ }^{11}$ and guest-responsive porosity, ${ }^{12}$ network catenation has proven to be advantageous. However, because noncatenated systems offer larger apertures and pores than their catenated counterparts, they are typically preferred in applications, such as chemical catalysis ${ }^{7}$ and high-pressure gas storage. ${ }^{4}$

While obtaining phase-pure, noncatenated MOFs is typically a challenging task, several strategies, suitable for specific systems or sets of systems, have been devised. For example, we have developed a method that allows for the separation of catenated and noncatenated MOFs based on density differences. ${ }^{13}$ Yaghi and co-workers have synthesized catenated and noncatenated IRMOFs separately by adjusting concentrations of reactants. ${ }^{14}$ Zaworotko and co-workers studied the influence of both reaction temperature and starting material concentrations on the extent of subsequent catenation. ${ }^{15}$ Bureekaew et al. ${ }^{10}$ and Song et al. ${ }^{16}$ have shown that the degree of catenation of certain flexible frameworks can be modulated by using solvent molecules as templates. Similarly, the utilization of oxalic acid as a templating agent allowed Zhou and co-workers to produce noncatenated PCN-6' in place of catenated PCN$6{ }^{17}$ Another interesting approach involves modification of the linker with a bulky pendant arm that, first, prevents catenation and, second, carries a catalytically active functional group. ${ }^{18}$ It has also been shown that MOFs can be constructed using nets for which catenation is geometrically precluded (e.g., most nonself-dual nets). ${ }^{19}$ The applicability of a sonochemical method for catenation control has been demonstrated in the synthesis of the PCN-6' / PCN-6 pair, as well as IRMOF-9 and IRMOF-10. ${ }^{20}$ Shekhah et al. have shown that they can suppress catenation by using "liquid-phase epitaxy" on an organic template and then employing a step-by-step growth method. ${ }^{21}$

Received: November 20, 2012

Revised: February 6, 2013

Published: February 9, 2013 
Finally, we have described an alternative approach to catenation control based on linker L2. Compared to L1, this linker incorporates additional steric blockage in the $x y$ plane, thereby precluding catenation (Figure 1). ${ }^{22}$ This modification allowed

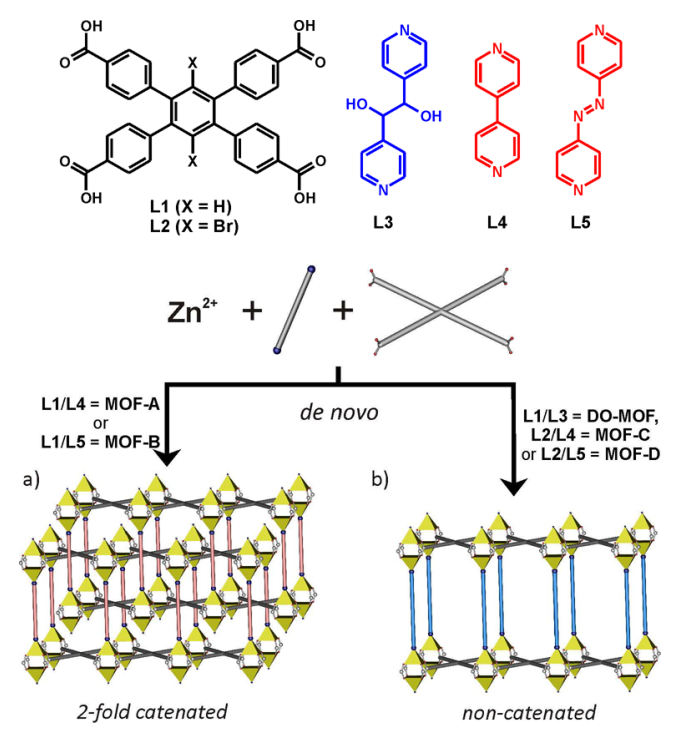

Figure 1.

us to construct a series of noncatenated MOFs, where, under otherwise identical synthesis conditions, L1 in combination with $\mathbf{L} \mathbf{4}$ or $\mathbf{L} \mathbf{5}$ produced 2 -fold catenated structures (Figure 1a).

Interestingly, the combination of $\mathbf{L} 1$ with a $\mathrm{Zn}$ (II) source and the diol-containing strut, L3, gave a material, DO-MOF, which consists of a single network (Figure $1 \mathrm{~b}$ ). ${ }^{23}$ From this finding as well as findings from other studies, we concluded that the steric demands of the carboxylate linker as well as the chemical properties of the dipyridyl moiety play a significant role in defining the degree of catenation of crystalline frameworks. In particular, the use of either a hydrogen-bonding capable (diol-containing) dipyridyl linker L3 or a sterically demanding linker (e.g., porphyrin-based ${ }^{24}$ or trimethylsilaneprotected $^{25}$ ) led to noncatenated structures. Note that noncatenated MOFs based on L2, while closely similar in overall chemical composition to those obtained with $\mathbf{L} \mathbf{1}$, are not identical. The noncatenated structures include two bromines per tetracarboxylate linker, while the catenated ones do not. Therefore, we sought to devise an alternative method capable of yielding truly chemically identical sets of catenated and noncatenated networks.

We hypothesized that the replacement of dipyridyl struts in noncatenated paddlewheel-type MOFs would lead to the formation of noninterpenetrated daughter structures containing new struts and that the daughter struts would retain crystallinity and porosity (Figure 2). Herein, we demonstrate our approach for the construction of noncatenated MOF materials through a single-crystal-to-single-crystal approach termed solvent-assisted linker exchange (SALE). The recently developed SALE process has been used to grow new materials unattainable by means of traditional solvothermal synthesis techniques. The fundamental concept of the linker-exchange methodology was presented by Choe and co-workers, ${ }^{26}$ and subsequently our group, ${ }^{27}$ in the context of porphyrin-based MOFs. It was further exemplified, expanded, and mechanistically elucidated by Cohen and coworkers, chiefly for UiO-66-type MOF materials, but also for a ZIF compound. ${ }^{28}$ Very recently, our group also reported on the

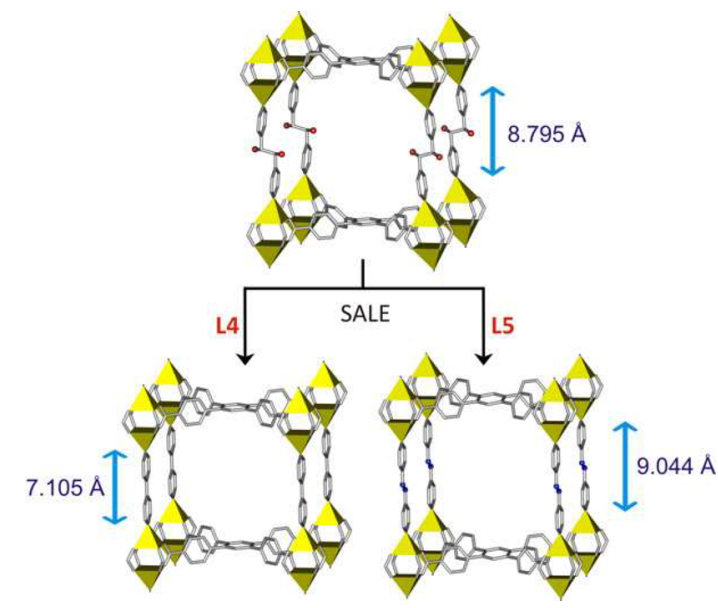

Figure 2.

use of the SALE method for the synthesis of crystalline ZIFs, namely, SALEM-1 and SALEM-2, starting from CdIF-4 and ZIF-8, respectively, where the topologies of the parent materials are retained. ${ }^{29}$ Notably, SALEM-1 and SALEM-2 appear to be inaccessible via conventional synthesis approaches. Additionally, we have used the SALE strategy to obtain mixedporphyrin MOFs that we were unable to synthesize directly. ${ }^{30}$

\section{EXPERIMENTAL SECTION}

Materials. Zinc nitrate hexahydrate (Fluka, 99\%), meso-1,2-di(4pyridyl)-1,2-ethanediol (TCI, 98\%) (L3), 4,4'-dipyridyl (Aldrich, 98\%), $N, N^{\prime}$-dimethylformamide (DMF) (Macron, 99.8\%), hydrochloric acid (Aldrich, 37\%), nitric acid (Aldrich, 70\%), deuterated dimethylsulfoxide ( $d_{6}$-DMSO) (Cambridge, 99\%), and deuterated sulfuric acid $\left(\mathrm{D}_{2} \mathrm{SO}_{4}\right)$ (Cambridge, $96-98 \%$ solution in $\mathrm{D}_{2} \mathrm{O}$ ) were used as received. The synthesis of $\mathbf{L} 1$ and $\mathbf{L 5}$ has been previously reported. 22

Instrumentation. ${ }^{1} \mathrm{H}$ NMR spectra were recorded on a $500 \mathrm{MHz}$ Varian INOVA spectrometer and referenced to the residual solvent peak. Powder X-ray diffraction (PXRD) patterns for capillaryencapsulated samples were obtained at room temperature with a Bruker MX I $\mu \mathrm{S}$ microsource ( $\mathrm{Cu} \mathrm{K} \alpha$ radiation) and an Apex II CCD detector. Samples were mounted in capillaries with supernatant liquid; capillaries were sealed with wax and placed on goniometer heads for mounting on the diffractometer ("spinning capillary" technique was employed). ${ }^{24 b, 31}$ The PXRD data were collected with an area detector as rotation frames over $180^{\circ}$ in $\varphi$ at $2 \theta$ values of 12,24 , and $36^{\circ}$ and exposed for $10 \mathrm{~min}$ for each frame. At a distance of $150 \mathrm{~mm}$, the detector area covers $24^{\circ}$ in $2 \theta$. Overlapping sections of data were matched, and the resulting pattern was integrated using the Bruker APEX2 phase ID program. Powder pattern data were treated for amorphous background scatter. Images of the single crystals were collected using a Nikon SMZ1500 stereozoom microscope equipped with a digital camera and video monitor for visualization of crystalline samples. Thermogravimetric analysis-mass spectrometry (TGA-MS) was performed on a Mettler Toledo TGA/DSC 1 interfaced with a PC and equipped with an SEM detector using Star and Quadera software. Samples of $\sim 10 \mathrm{mg}$ were heated from 25 to $700{ }^{\circ} \mathrm{C}$ at a rate of $10{ }^{\circ} \mathrm{C} /$ min under a nitrogen atmosphere.

Synthesis of DO-MOF. We modified a procedure from ref 23 . Briefly, DO-MOF was obtained upon heating $\mathrm{Zn}\left(\mathrm{NO}_{3}\right)_{2} \times 6 \mathrm{H}_{2} \mathrm{O}(50$ $\mathrm{mg}, 0.17 \mathrm{mmol}), \mathbf{L} 1(100 \mathrm{mg}, 0.18 \mathrm{mmol})$, and L3 (50 mg, 0.24 $\mathrm{mmol}$ ) in $25 \mathrm{~mL}$ of DMF with one drop of concentrated HCl. This solution was divided equally between five 4-dram screw cap vials and heated to $80^{\circ} \mathrm{C}$ for 3 days, at which time clear colorless block crystals had formed. DO-MOF crystals were collected and washed with DMF. The crystals were stored in DMF until needed for experiments. Phase 
purity was verified by ${ }^{1} \mathrm{H}$ NMR, PXRD, and TGA (Figures S1, S6, and S11, Supporting Information).

Synthesis of SALEM-3/SALEM-4 via SALE. DO-MOF crystals were dried on a filter paper $(72 \mathrm{mg}, 0.08 \mathrm{mmol})$ and placed in a 2dram screw cap vial, and a DMF solution $(2 \mathrm{~mL})$ of $\mathbf{L 4}(50 \mathrm{mg}, 0.32$ $\mathrm{mmol}$ ) or L5 (59 mg, $0.32 \mathrm{mmol}$ ) was added. The vial was capped and placed in an isothermal oven at $80{ }^{\circ} \mathrm{C}$. The progress of the linkerexchange reaction was monitored by ${ }^{1} \mathrm{H}$ NMR. For SALEM-3, the linker exchange was complete after $24 \mathrm{~h}$. The synthesis of SALEM-4 required replacement of the solution of $\mathbf{L 5}$ every $24 \mathrm{~h}$ (three exchange cycles).

Synthesis of MOF-A and MOF-B de novo. Crystalline samples of 2-fold catenated materials MOF-A and MOF-B were synthesized according to a previously reported procedure. ${ }^{22}$

NMR of SALEM-3 and SALEM-4 Samples. Approximately $5 \mathrm{mg}$ of SALEM-3 or SALEM-4 was placed in a 2-dram vial and dissolved in $0.6 \mathrm{~mL}$ of $d_{6}$-DMSO with 2 drops of $\mathrm{D}_{2} \mathrm{SO}_{4}$ by sonication. Once a homogeneous solution was obtained, the sample was transferred to an NMR tube. ${ }^{1} \mathrm{H}$ NMR spectra were obtained by locking the sample to $d_{6}$-DMSO.

Structure Prediction for SALEM-3 and SALEM-4. Noncatenated, orthorhombic, MOF-C and MOF-D structures (Figure 1) with $P m m m$ and $P 2 / m$ space groups, ${ }^{22}$ respectively, were used as the initial models for building noncatenated structures of SALEM-3 and SALEM-4 for geometric optimizations ( $\mathrm{Br}$ atoms in MOF-C and MOF-D where substituted by $\mathrm{H}$ atoms). The lattice parameters (SALEM-3: $a=11.6425 \AA, b=13.8569 \AA$, $c=15.5738 \AA$; SALEM-4: $a=11.6533 \AA, b=c=15.5738 \AA$ ) were modified according to the experimental PXRD. Thereafter, the structures were subject to geometry optimization based on molecular mechanics calculations, modifying all the atomic positions. These calculations were performed with the Forcite module of Materials Studio, using an algorithm that is a cascade of the steepest descent, adjusted basis set Newton-Raphson, and quasi-Newton methods. ${ }^{32}$ The bonded and the short-range (van der Waals) nonbonded interactions between the atoms were modeled using the Universal Force Field (UFF). ${ }^{33}$ In UFF, bond stretching is described by a harmonic term, angle bending by a three-term Fourier cosine expansion, torsions and inversions by cosine-Fourier expansion terms, and the van der Waals interactions by the Lennard-Jones (LJ) potential. A cutoff distance of $12 \AA$ was used for the LJ interactions. The long-range, electrostatic, interactions, arising from the presence of partial atomic charges, were modeled using a Coulombic term. The Ewald sum method was used to compute the electrostatic interactions. Partial atomic charges were derived from the charge equilibration method $(\mathrm{QEq})^{34}$ as implemented in Forcite.

\section{RESULTS AND DISCUSSION}

We have synthesized noncatenated MOFs via SALE utilizing a noncatenated framework, DO-MOF, as the parent material. DO-MOF is a paddlewheel-type MOF containing large cavities with a solvent-accessible void volume of $76 \%$ (based on PLATON calculations) and readily accessible alcohol functionalities. DO-MOF was synthesized according to a modified procedure published previously by our group, ${ }^{23}$ and the purity was confirmed by powder X-ray diffraction (PXRD) (Figure S6, Supporting Information). Thermogravimetric analysis-mass spectrometry (TGA-MS) data for a freshly prepared DOMOF show a sizable mass loss below $200{ }^{\circ} \mathrm{C}$ and a smaller loss in the range of $290-360{ }^{\circ} \mathrm{C}$ (49\% and $10 \%$, respectively) (Figure S11, Supporting Information). We attribute these to stepwise removal of $N, N$-dimethylformamide (DMF) molecules, where the loss at $290{ }^{\circ} \mathrm{C}$ likely corresponds to the expulsion of DMF molecules bound to alcohol functionalities by hydrogen bonds. We speculatively suggest that the solvent molecules bound to the alcohol groups increase the steric demands of the pillars and, as a result, prevent catenation during MOF formation.
Prior to SALE, crystals of the parent DO-MOF were soaked for $12 \mathrm{~h}$ in fresh DMF to remove residual impurities, and then briefly dried on filter paper. To perform the linker exchange, DO-MOF was immersed in a DMF solution of L4 (4-fold excess) and placed in an oven at $80{ }^{\circ} \mathrm{C}$. After $24 \mathrm{~h}$, the ${ }^{1} \mathrm{H}$ NMR spectrum of representative parent crystals (rinsed, dried, and dissolved in $\mathrm{D}_{2} \mathrm{SO}_{4} / d_{6}$-DMSO mixture) showed that $100 \%$ of the L3 linkers had been replaced by L4 (Figure 3, spectrum b). On the basis of ${ }^{1} \mathrm{H}$ NMR spectroscopy, the exchange with L4 proceeded relatively quickly.

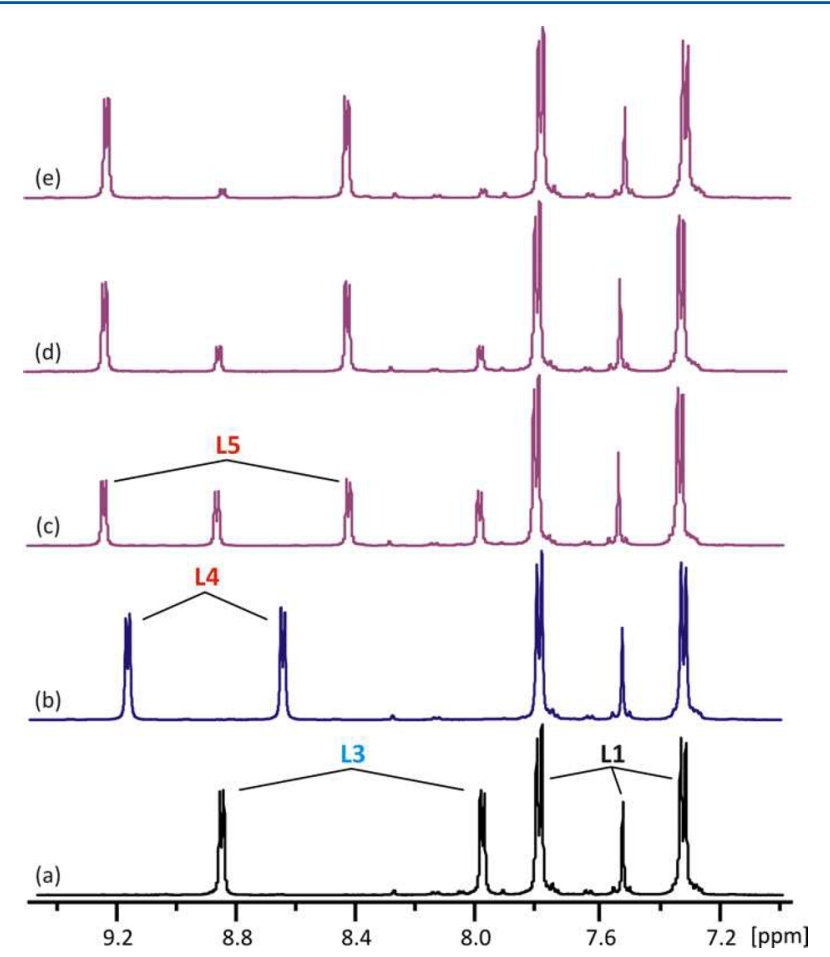

Figure 3. Progress of the $\mathbf{L} 4$ and $\mathbf{L 5}$ linker-exchange processes in DOMOF, monitored by ${ }^{1} \mathrm{H}$ NMR spectroscopy $\left(\mathrm{D}_{2} \mathrm{SO}_{4} / d_{6}\right.$-DMSO, 25 $\left.{ }^{\circ} \mathrm{C}\right)$ : (a) parent DO-MOF material, (b) reaction with L4 after $24 \mathrm{~h}$ (100\% exchange), and reaction with L5 after (c) $24 \mathrm{~h}$ (55\% exchange), (d) $48 \mathrm{~h}$ (76\% exchange), and (e) $72 \mathrm{~h}$ ( $92 \%$ exchange).

Encouraged by these results, we decided to investigate SALE with L5. In contrast to L4, which is shorter than the pillaring linker in DO-MOF, L5 is equal in length. Treatment of a fresh sample of DO-MOF with a DMF solution containing a 4-fold excess of L5 showed that, after $24 \mathrm{~h}$, only $55 \%$ of the parent linker had been replaced (Figure 3, spectrum c). (Extending the soaking time to $48 \mathrm{~h}$ did not measurably increase the extent of exchange, thus implying that equilibrium had been reached.) Repeating the procedure with a fresh solution of the L5 yielded, after an additional $24 \mathrm{~h}, 76 \%$ linker exchange (Figure 3, spectrum d). Following a third $24 \mathrm{~h}$ exposure (again with a new solution of L5), a 92\% linker replacement was obtained (Figure 3 , spectrum e). The difference in extent of exchange is most readily interpreted in terms of differences in linker Brönsted basicity (a proxy for relative linker-metal bond strength), with the basicity of $\mathbf{L} 4$ being similar to that of $\mathbf{L} 3$ and exceeding that of $\mathbf{L 5}{ }^{35}$ An additional factor might be the substantial difference in strut length for L3 versus L4 strut.

To confirm the noncatenated nature of the linker-exchanged materials, we attempted to obtain single-crystal data. Unfortunately, our efforts to obtain high-quality crystals of SALEM-3 
and SALEM-4 for single-crystal X-ray diffraction studies were unsuccessful. Therefore, the structures of SALEM-3 and SALEM-4 were modeled from PXRD data using a procedure described previously (see the Experimental Section and the Supporting Information). ${ }^{4 a, 36}$ First, PXRD revealed that SALEM-3 and SALEM-4 maintained their crystallinity after SALE (Figure 4); then, noncatenated SALEM-3 and SALEM-4
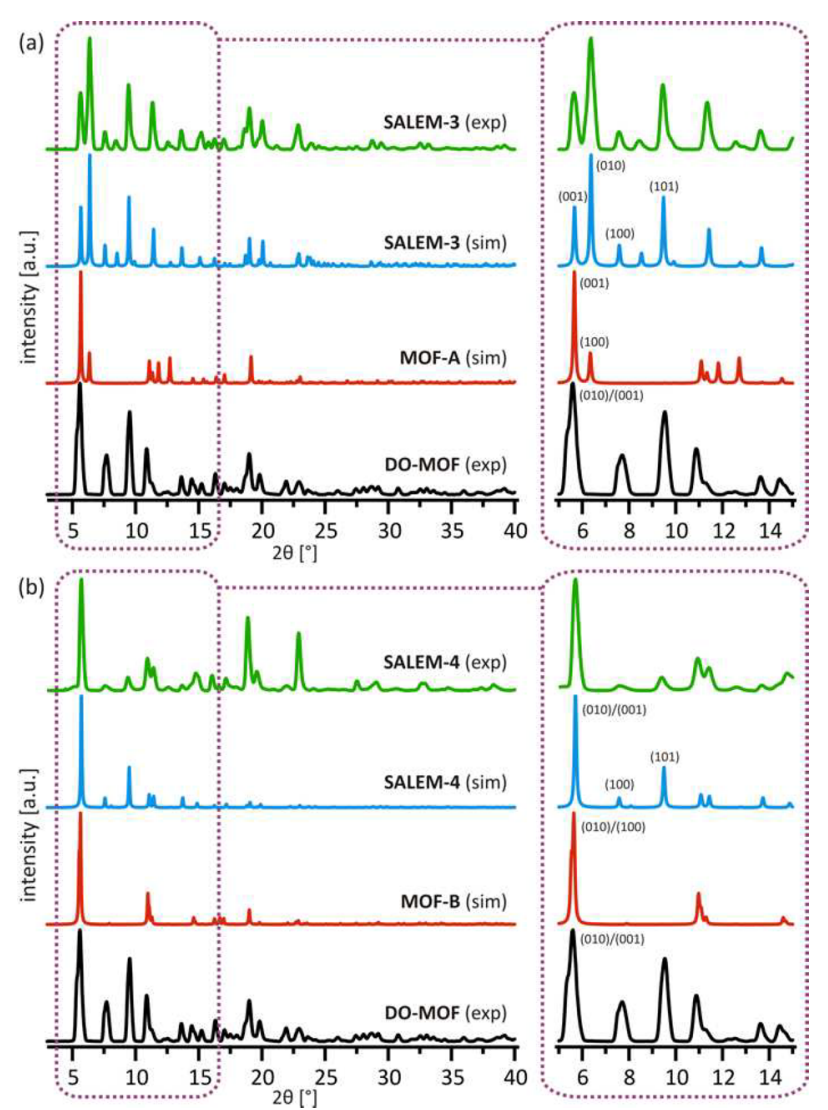

Figure 4. Experimental and simulated PXRD patterns of the linkerexchange noncatenated daughter materials SALEM-3 (a) and SALEM4 (b), as well as their 2-fold catenated counterparts MOF-A and MOF-B, respectively. For comparison, the experimental PXRD pattern of the parent DO-MOF is included as well.

structures were initially constructed (in silico) on the basis of their analogues containing $\mathbf{L} 2$. The bromine atoms on $\mathbf{L} 2$ were replaced by hydrogen atoms, and the structures were optimized using the lattice parameters obtained from the experimental PXRD patterns (lattice parameters: SALEM-3: Pmmm, $a=$ 11.6425 $\AA, b=13.8569 \AA, c=15.5738 \AA$ A SALEM-4: $P 2 / m, a=$ $11.6533 \AA, b=c=15.5738 \AA$ ). Figure $4 \mathrm{a}, \mathrm{b}$ compares the experimental PXRD patterns of SALEM-3 and -4, respectively, with the simulated patterns obtained for the 2-fold catenated (MOF-A: L2/L4 and MOF-B: L2/L5) ${ }^{22}$ and noncatenated computational models. In both cases, only the noncatenated model is able to fully match all the peak positions and intensities of the experimental patterns, whereas the catenated ones lack multiple peaks. It is worth noting that the observed [010] reflection in DO-MOF describes the spacing between the 2D sheets formed by $\mathbf{L} \mathbf{1}$ and is correlated to the length of the pillaring linker, L3. In the case of SALEM-3, the $[001] /[010]$ peak splits into two new peaks, but not in SALEM-4 since L3 and L5 are of similar length. In SALEM-3, the [010] peak is shifted to higher $2 \theta$ when compared to the PXRD pattern of the DO-MOF. This agrees with the reduction of spacing between $2 \mathrm{D}$ sheets during the linker-exchange process.

To support our findings from PXRD analysis, we measured and compared TGA profiles for samples synthesized de novo as well as via the SALE approach. TGA curves for linker-exchange materials SALEM-3 and SALEM-4 revealed the mass loss in the temperature range of $25-250{ }^{\circ} \mathrm{C}$ of $54 \%$ and $45 \%$, respectively (Figure 5 and Figure S13, Supporting Information,

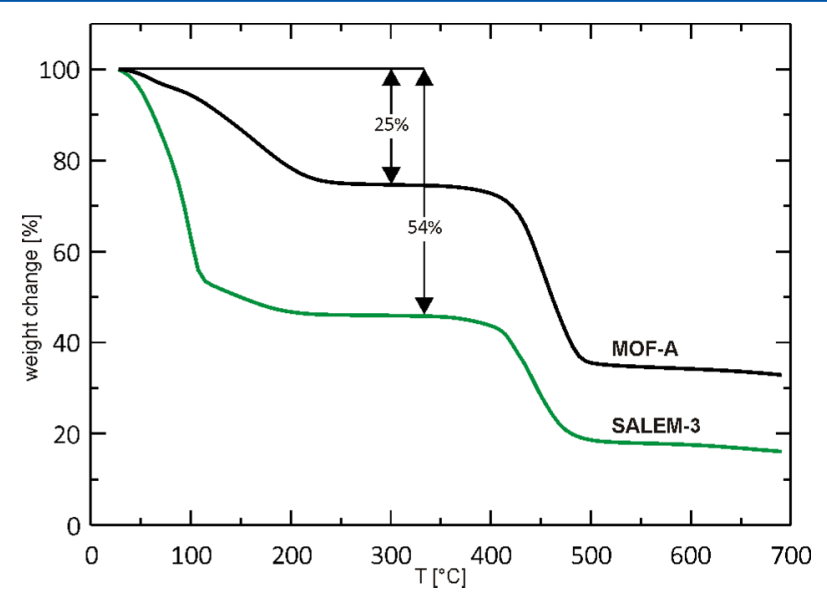

Figure 5. TGA profiles of the linker-exchange material SALEM-3 and de novo synthesized MOF-A.

respectively). For the de novo synthesized material MOF-A, the TGA profile showed much less solvent loss (ca. 25\%), consistent with its known 2-fold catenated structure. Similar comparison for SALEM-4 and its 2-fold catenated polymorph MOF-B gave solvent loss values of $45 \%$ and $29 \%$, respectively (Figure S13, Supporting Information).

To gain additional insight into the mechanism of SALE in DO-MOF, similar exchange experiments were performed on single crystals of the parent material. DO-MOF crystals were placed in a solution of $\mathbf{L 4}$ and $\mathbf{L 5}$ at $80{ }^{\circ} \mathrm{C}$. We selected 15 crystals of the parent material and soaked them in a DMF solution of L4 (colorless). After $24 \mathrm{~h}$, the same number of crystals was observed without any noticeable changes in their size or morphology. A similar experiment was conducted using L5 (red color). In this case, the linker-exchange progress can be easily monitored by the change of the parent material from colorless to dark orange (Figure 6). These observations clearly indicate that SALE in DO-MOF can be regarded as a crystal-tocrystal transformation.

\section{CONCLUSIONS}

In conclusion, we find that a representative pair of noncatenated, pillared paddlewheel-type MOF materials that

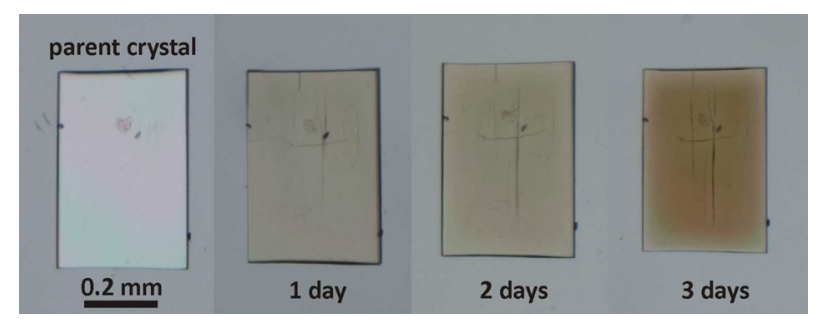

Figure 6. Photographs of SALE progress in DO-MOF crystal with L5 linker. 
previously could be synthesized only in 2-fold catenated form can now be accessed in single-network (i.e., noncatenated) form. The new polymorphs, SALEM-3 and SALEM-4, were accessed via solvent-assisted linker exchange of a previously reported material, DO-MOF. TGA measurements show that the void spaces within the noncatenated versions contain roughly twice the amount of solvent as do the void spaces within the catenated compounds. While the reported examples center only on pillar exchange, it seems reasonable to expect that the SALE technique will prove useful for synthesizing, in single-network form, other types of MOFs that have thus far been obtainable only as catenated compounds.

\section{ASSOCIATED CONTENT}

\section{S Supporting Information}

${ }^{1} \mathrm{H}$ NMR spectra, PXRD patterns, and TGA data of the SALE products (PDF) and CIF files. This material is available free of charge via the Internet at http://pubs.acs.org.

\section{AUTHOR INFORMATION}

\section{Corresponding Author}

*E-mail: j-hupp@northwestern.edu (J.T.H.), o-farha@ northwestern.edu (O.K.F.).

\section{Notes}

The authors declare no competing financial interest.

\section{ACKNOWLEDGMENTS}

We gratefully acknowledge the U.S. Dept. of Energy, Office of Science, Basic Energy Sciences (grant DE-FG2-08ER15967); the Defense Threat Reduction Agency (HDTRA1-10-1-0023; computational modeling by D.F.-J. and R.Q.S.); the Polish Ministry of Science and Higher Education through the "Mobility Plus" Program (W.B.); and the Royal Society (U.K.) through a University Research Fellowship (to D.F.-J.), for support of this work.

\section{REFERENCES}

(1) (a) Horike, S.; Shimomura, S.; Kitagawa, S. Nat. Chem. 2009, 1, 695-704. (b) Ferey, G. Chem. Soc. Rev. 2008, 37, 191. (c) Tranchemontagne, D. J.; Mendoza-Cortes, J. L.; O’Keeffe, M.; Yaghi, O. M. Chem. Soc. Rev. 2009, 38, 1257-1283.

(2) Farha, O. K.; Eryazici, I.; Jeong, N. C.; Hauser, B. G.; Wilmer, C. E.; Sarjeant, A. A.; Snurr, R. Q.; Nguyen, S. T.; Yazaydin, A. Ö.; Hupp, J. T. J. Am. Chem. Soc. 2012, 134, 15016-15021.

(3) (a) Li, J.-R.; Kuppler, R. J.; Zhou, H.-C. Chem. Soc. Rev. 2009, 38, 1477-1504. (b) Murray, L. J.; Dinca, M.; Long, J. R. Chem. Soc. Rev. 2009, 38, 1294-1314. (c) Suh, M. P.; Park, H. J.; Prasad, T. K.; Lim, D.-W. Chem. Rev. 2012, 112, 782-835.

(4) (a) Farha, O. K.; Yazaydin, O.; Eryazici, I.; Malliakas, C.; Hauser, B.; Kanatzidis, M. G.; Nguyen, S. T.; Snurr, R. Q.; Hupp, J. T. Nat. Chem. 2010, 2, 944-948. (b) Furukawa, H.; Ko, N.; Go, Y. B.; Aratani, N.; Choi, S. B.; Choi, E.; Yazaydin, A. Ö.; Snurr, R. Q.; O’Keeffe, M.; Kim, J.; Yaghi, O. M. Science 2010, 329, 424-428.

(5) (a) Kreno, L. E.; Leong, K.; Farha, O. K.; Allendorf, M.; Van Duyne, R. P.; Hupp, J. T. Chem. Rev. 2012, 112, 1105-1125. (b) Allendorf, M. D.; Bauer, C. A.; Bhakta, R. K.; Houk, R. J. T. Chem. Soc. Rev. 2009, 38, 1330-1352.

(6) (a) Lu, G.; Hupp, J. T. J. Am. Chem. Soc. 2010, 132, 7832. (b) Kreno, L. E.; Hupp, J. T.; Van Duyne, R. P. Anal. Chem. 2010, 82, 8042-8046.

(7) (a) Lee, J.; Farha, O. K.; Roberts, J.; Scheidt, K. A.; Nguyen, S. T.; Hupp, J. T. Chem. Soc. Rev. 2009, 38, 1450-1459. (b) Ma, L.; Abney, C.; Lin, W. Chem. Soc. Rev. 2009, 38, 1248-1256. (c) Yoon, M.; Srirambalaji, R.; Kim, K. Chem. Rev. 2012, 112, 1196-1231.

(8) Batten, R. S. CrystEngComm 2001, 3, 67-72.
(9) Kim, H.; Suh, M. P. Inorg. Chem. 2005, 44, 810-812.

(10) Bureekaew, S.; Sato, H.; Matsuda, R.; Kubota, Y.; Hirose, R.; Kim, J.; Kato, K.; Takata, M.; Kitagawa, S. Angew. Chem., Int. Ed. 2010, 49, 7660-7664.

(11) Takashima, Y.; Martinez, V. M.; Furukawa, S.; Kondo, M.; Shimomura, S.; Uehara, H.; Nakahama, M.; Sugimoto, K.; Kitagawa, S. Nat. Commun. 2011, 2, 168.

(12) Maji, T. K.; Matsuda, R.; Kitagawa, S. Nat. Mater. 2007, 6, 142148.

(13) (a) Farha, O. K.; Mulfort, K. L.; Thorsness, A. M.; Hupp, J. T. J. Am. Chem. Soc. 2008, 130, 8598-8599. (b) Farha, O. K.; Hupp, J. T. Acc. Chem. Res. 2010, 43, 1166-1175.

(14) Eddaoudi, M.; Kim, J.; Rosi, N. L.; Vodak, D. T.; Wachter, J.; O'Keeffe, M.; Yaghi, O. M. Science 2002, 295, 469-472.

(15) Zhang, J. J.; Wojtas, L.; Larsen, R. W.; Eddaoudi, M.; Zaworotko, M. J. J. Am. Chem. Soc. 2009, 131, 17040-17041.

(16) Song, F.; Wang, C.; Falkowski, J. M.; Ma, L.; Lin, W. J. Am. Chem. Soc. 2010, 132, 15390-15398.

(17) Ma, S.; Sun, D.; Ambrogio, M.; Fillinger, J. A.; Parkin, S.; Zhou, H. C. J. Am. Chem. Soc. 2007, 129, 1858-1859.

(18) (a) Lun, D. J.; Waterhouse, G. I. N.; Telfer, S. G. J. Am. Chem. Soc. 2011, 133, 5806-5809. (b) Roberts, J. M.; Farha, O. K.; Sarjeant, A. A.; Hupp, J. T.; Scheidt, K. A. Cryst. Growth Des. 2011, 11, 47474750 .

(19) (a) Chae, H. K.; Siberio-Pérez, D. Y.; Kim, J.; Go, Y.; Eddaoudi, M.; Matzger, A. J.; O'Keeffe, M.; Yaghi, O. M. Nature 2004, 427, 523527. (b) Rosi, N. L.; Eddaoudi, M.; Kim, J.; O'Keeffe, M.; Yaghi, O. M. Angew. Chem., Int. Ed. 2002, 41, 284-287.

(20) Kim, J.; Yang, S.-T.; Choi, S. B.; Sim, J.; Kim, J.; Ahn, W.-S. J. Mater. Chem. 2011, 21, 3070-3076.

(21) Shekhah, O.; Wang, H.; Paradinas, M.; Ocal, C.; Schüpbach, B.; Terfort, A.; Zacher, D.; Fischer, R. A.; Wöll, C. Nat. Mater. 2009, 8, $481-484$.

(22) For the synthesis of $\mathbf{L} \mathbf{1}$, the procedure in the following paper should be used: (a) Farha, O. K.; Malliakas, C. D.; Kanatzidis, M. G.; Hupp, J. T. J. Am. Chem. Soc. 2010, 132, 950-952. The procedure described in our previous paper may over-pressurize the reaction vessel; see: (b) Farha, O. K.; Mulfort, K. L.; Hupp, J. T. Inorg. Chem. 2008, 47, 7936-7938.

(23) Mulfort, K. L.; Farha, O. K.; Stern, C. L.; Sarjeant, A. A.; Hupp, J. T. J. Am. Chem. Soc. 2009, 131, 3866-3868.

(24) (a) Shultz, A. M.; Farha, O. K.; Hupp, J. T.; Nguyen, S. T. J. Am. Chem. Soc. 2009, 131, 4204-4205. (b) Farha, O. K.; Shultz, A. M.; Sarjeant, A. A.; Nguyen, S. T.; Hupp, J. T. J. Am. Chem. Soc. 2011, 133, $5652-5655$.

(25) Gadzikwa, T.; Farha, O. K.; Malliakas, C. D.; Kanatzidis, M. G.; Hupp, J. T.; Nguyen, S. T. J. Am. Chem. Soc. 2009, 131, 13613-13615.

(26) Burnett, B. J.; Barron, P. M.; Hu, C.; Choe, W. J. Am. Chem. Soc. 2011, 133, 9984-9987.

(27) Lee, C. Y.; Farha, O. K.; Hong, B. J.; Sarjeant, A. A.; Nguyen, S. T.; Hupp, J. T. J. Am. Chem. Soc. 2011, 133, 15858-15861.

(28) (a) Kim, M.; Cahill, J. F.; Su, Y.; Prather, K. A.; Cohen, S. M. Chem. Sci. 2012, 3, 126-130. (b) Kim, M.; Cahill, J. F.; Fei, H.; Prather, K. A.; Cohen, S. M. J. Am. Chem. Soc. 2012, 134, 1808218088.

(29) (a) Karagiaridi, O.; Bury, W.; Sarjeant, A. A.; Stern, C. L.; Farha, O. K.; Hupp, J. T. Chem. Sci. 2012, 3, 3256-3260. (b) Karagiaridi, O.; Lalonde, M. B.; Bury, W.; Sarjeant, A. A.; Farha, O. K.; Hupp, J. T. J. Am. Chem. Soc. 2012, 134, 18790-18796.

(30) Takaishi, S.; DeMarco, E. J.; Pellin, M. J.; Farha, O. K.; Hupp, J. T. Chem. Sci. 2013. DOI: 10.1039/C2SC21516K.

(31) Shultz, A. M.; Sarjeant, A. A.; Farha, O. K.; Hupp, J. T.; Nguyen, S. T. J. Am. Chem. Soc. 2011, 133, 13252-13255.

(32) Materials Studio 5.0; Accelrys Software Inc.: San Diego, CA, 2009.

(33) Rappé, A. K.; Casewit, C. J.; Colwell, K. S.; Goddard, W. A.; Skiff, W. M. J. Am. Chem. Soc. 1992, 114, 10024-10035.

(34) Rappé, A. K.; Goddard, W. A., III J. Phys. Chem. 1991, 95, 3358. 
(35) (a) The $\mathrm{pK}_{\mathrm{a}}$ values for monoprotonated linkers L3, L4, and L5 are estimated to be 5.29, 5.25 and 4.23 , respectively. The estimates were obtained by using: $\mathrm{pK}_{\mathrm{a}}$ Calculator Plugin , Marvin 5.8.0; ChemAxon, 2012. http://www.chemaxon.com. For the details of the method of estimation of $\mathrm{pK}_{\mathrm{a}}$ values (an approach based on calculated atomic charges), see: (b) Dixon, S. L.; Jurs, P. C. J. Comput. Chem. 1993, 14, 1460-1467.

(36) (a) Strutt, N. L.; Fairen-Jimenez, D.; Iehl, J.; Lalonde, M. B.; Snurr, R. Q.; Farha, O. K.; Hupp, J. T.; Stoddart, J. F. J. Am. Chem. Soc. 2012, 134, 17436-17439. (b) Fairen-Jimenez, D.; Colon, Y. J.; Farha, O. K.; Bae, Y.-S.; Hupp, J. T.; Snurr, R. Q. Chem. Commun. 2012, 48, 10496-10498. 